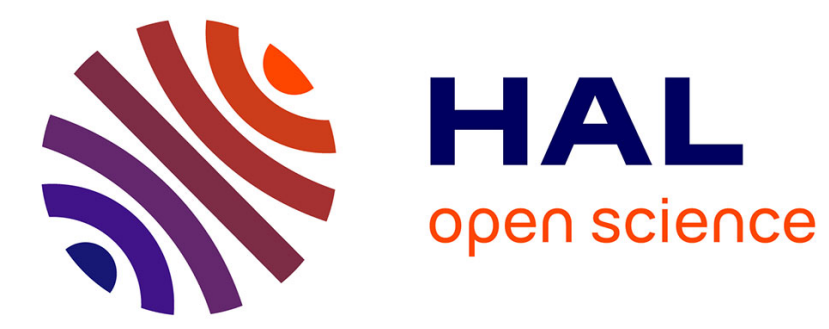

\title{
ÉLOIGNER LE SOLDAT DU CIVIL EN TEMPS DE GUERRE
}

\author{
Pierre-Jean Souriac
}

\section{To cite this version:}

Pierre-Jean Souriac. ÉLOIGNER LE SOLDAT DU CIVIL EN TEMPS DE GUERRE. Revue historique, 2004, 4 (306), 10.3917/rhis.044.0787 . halshs-01228479

\section{HAL Id: halshs-01228479 \\ https://shs.hal.science/halshs-01228479}

Submitted on 11 Sep 2017

HAL is a multi-disciplinary open access archive for the deposit and dissemination of scientific research documents, whether they are published or not. The documents may come from teaching and research institutions in France or abroad, or from public or private research centers.
L'archive ouverte pluridisciplinaire HAL, est destinée au dépôt et à la diffusion de documents scientifiques de niveau recherche, publiés ou non, émanant des établissements d'enseignement et de recherche français ou étrangers, des laboratoires publics ou privés. 


\section{Eloigner le soldat du civil en temps de guerre \\ Les expériences de trêves en Midi toulousain dans les dernières années des guerres de Religion}

Pierre-Jean Souriac

Université de Paris IV - Sorbonne

Revue historique, 306/4, décembre 2004, p. 788-818

Les paix qui suivirent les guerres de Religion en France avaient-elles pour ambition de solder une guerre civile en tenant compte du bilan des opérations ou cherchaient-elles à définir, voire redéfinir, un ordre social que des troubles intérieurs avaient mis à mal ? Les récents travaux sur le problème des pacifications interconfessionnelles en Europe au XVI ${ }^{\mathrm{e}}$ siècle, ainsi que la vague de publications qui suivit la commémoration de l'Edit de Nantes en 1998, montrent combien l'enjeu de ces textes législatifs fut de définir un modus vivendi au plus près des questions quotidiennes posées par le voisinage contraint des catholiques et des protestants ${ }^{1}$. Le problème des paix de Religion fut essentiellement celui de la coexistence confessionnelle visant à repousser toute menace d'affrontement et oublier celle qui venait de s'accomplir. Ce fut la grande affaire des dirigeants du royaume dès les premiers bruits de trouble : l'Edit de Janvier 1562, premier texte de ce genre en France, chercha à régler la vie des catholiques et des protestants dans les villes et les campagnes françaises avant même que les guerres proprement dites aient véritablement commencé ${ }^{2}$. Les sept édits qui suivirent, de la paix d'Amboise en 1563 à l'Edit de Nantes en 1598, avec des mots souvent proches mais dans des conjonctures différentes, n'eurent pas d'autres ambitions que cette recherche de coexistence. En ce sens, une paix de religion n'était en rien un traité militaire qui aurait prolongé par un acte juridique ce qui avait été gagné l'épée à la main, qui aurait entériné la situation issue du conflit, et aurait prolongé la mémoire du fait d'armes. Ainsi, elle n'était ni une capitulation, ni un traité de paix, encore moins un armistice dont l'objectif était de suspendre les combats.

Mais avant la pacification henricienne de la décennie 1590, ces projets de paix ne furent le plus souvent que des mirages pour la plupart des régions françaises où se côtoyaient les deux confessions. Le Midi toulousain - des Pyrénées à l'Albigeois, de Montauban à Castelnaudary, des collines de Gascogne aux terres castraises - fut le théâtre des ces efforts de conciliation autour d'un projet social en partie désacralisé, où la concorde civile définie par le juriste l'emportait sur la concorde religieuse définie par le théologien ; il fut aussi celui de leurs échecs. L'Edit de janvier 1562 s'ensuivit à Toulouse d'une occupation protestante de l'hôtel de ville, puis d'une violente répression menée par la majorité catholique qui finit dans un bain de sang ${ }^{3}$. Par la suite, l'espace régional se polarisa autour de frontières confessionnelles devenues des fronts mouvants de guerre civile : une zone d'intransigeance catholique se dessinait autour de la vallée de la Garonne, des Pyrénées à Toulouse en traversant le comté de Comminges, et se prolongeait vers Albi et son plat pays ; les bastions protestants se dressaient dans la périphérie toulousaine à Montauban, Castres

\footnotetext{
${ }^{1}$ CHRISTIN, Olivier, La paix de religion, l'autonomisation de la raison politique au XVIe siècle, Paris, Seuil, coll. "Liber", 1997 ; GRANDJEAN, Michel, ROUSSEL, Bernard (éd.), Coexister dans l'intolérance. L'édit de Nantes (1598), Genève, Labor et Fidès, coll. "Histoire et Société", 1998, 544 p. ; SAUPIN, Guy, FABRE, Rémy, LAUNAY, Marcel, La Tolérance. Colloque international de Nantes. Mai 1998. Quatrième centenaire de l'édit de Nantes, Rennes, PUR., 1999 ; L'édit de Nantes. Sûreté et éducation. Colloque de Montauban, octobre 1998, Montauban, 1999 ; EL KENZ, David, GANTET, Claire, Guerres et paix de religion en Europe. 16-17e siècle, Armand Colin, coll. "Cursus", 2003.

2 STEGMANN, André, Les édits des guerres de Religion, Paris, Vrin, 1979, p. 8 : édit de Saint-Germain - 17 janvier 1562.

${ }^{3}$ SOURIAC, Pierre-Jean, "Les urgeans affaires de la ville. Défendre Toulouse durant la première guerre de Religion", Revue d'bistoire urbaine, $\mathrm{n}^{\circ} 2$, juin 2001, p. 39-65.
} 
ainsi que dans le comté de Foix ${ }^{4}$. Il faut attendre la paix de Folembray signée fin janvier ou début février 1596 entre les Ligueurs languedociens et Henri IV pour trouver le texte qui mit fin aux conflits civils, au terme de la huitième guerre ${ }^{5}$. Il ne s'agissait pourtant pas d'une paix de religion, mais d'un traité militaire entre clans rivaux qui enregistrait la soumission du parti ligueur moyennant des garanties personnelles, financières et religieuses en faveur des contractants. Ce texte permettait de matérialiser le dépôt des armes avant que la question de la coexistence religieuse soit tranchée par un autre édit, signé à Nantes en 1598 : ainsi, il précédait de deux ans la paix de religion qui organisa pour le siècle à venir le modus vivendi entre catholiques et protestants.

C'est cette discordance entre paix militaire et paix de religion que nous aimerions examiner dans cet article : après 36 années de guerres civiles, la question de la résolution des conflits, en amont du problème de la coexistence confessionnelle, nous semble dépasser le seul problème de la définition des droits et devoirs des communautés rivales. Denis Crouzet voit dans la pacification d'Henri IV l'action d'un roi de Raison, venu à bout des passions ligueuses par une action rationnelle posée pour le bien général, perspective stö̈cienne d'une normalité inscrite dans la monarchie absolue et imposant une paix civile au dessus des querelles confessionnelles ${ }^{6}$. Nous nous proposons de chercher les traces de cette Raison, non pas dans la législation et l'action royale, mais dans les comportements provinciaux à l'égard des conflits et plus précisément dans la manière dont les sujets du roi de France, catholiques et protestants, cherchèrent à écarter de leur quotidien les malheurs de la guerre avant même qu'une paix ne soit arrêtée par les chefs de guerre. L'expression de cette Raison qui fit primer la paix civile sur le différend religieux, nous pensons l'avoir découverte dans une pratique militaire récurrente au sein des campagnes toulousaines : les accords de trêves de labourage qui ponctuèrent les années de guerre civile de 1586 à 1596. Tout au long de la huitième guerre de Religion, la plus longue et la plus dure, il ne se passa pas une année sans que les adversaires du moment ne se mettent en relation afin d'éviter que leurs affrontements n'aboutissent à la ruine du pays. Autour du problème de la guerre, se noua alors un dialogue qui sut s'affranchir de la question religieuse afin de traiter le problème militaire le plus urgent, à savoir la destruction des récoles, la ruine des villages ou les difficultés d'accomplir les travaux des champs à cause des armées de passage. C'est cette Raison des élites comme des petites gens du Midi toulousain qui pose la question de l'enracinement de la pacification du royaume, et montre le lent travail de maturation d'un nouvel ordre social inventé en réaction à la guerre civile.

\section{Origine et diffusion des trêves}

En termes militaires, la trêve équivaut à l'armistice : il s'agit d'une suspension d'armes qui engage l'autorité des chefs de guerre et cherche à arrêter les combats. Ces accords sont en général le prélude à la conclusion d'une paix plus stable et n'ont donc qu'un rôle transitoire ${ }^{7}$. Ces trêves de suspension d'armes ne furent pas absentes des guerres civiles parce qu'elles étaient un des moyens de mettre l'affrontement en suspens pour ouvrir une négociation. Le gouverneur de

\footnotetext{
${ }^{4}$ Cf. Annexe 3 : carte des trêves de labourage en Midi toulousain, pour une localisation générale.

${ }^{5}$ BnF., F-46898 (3) : Edit du roi sur la réduction de la ville de Tolose, et autres villes du pays de Languedoc et ressort du Parlement dudict Toulouse, Lyon, Thibaud Ancelin, 1596, 32 p. ; au sujet des dernières années de guerre civile, voir : GREENGRASS, Marc, "The later wars of Religion in the french Midi", dans CLARK, Peter, The European crisis of the 1590s, essays in comparative history, Londres, George Allen and Unwin, 1985, p. 106-134.

${ }^{6}$ CROUZET, Denis, Les guerriers de Dieux. La violence au temps des troubles de religion. Vers 1525-vers 1610, Seyssel, Champ Vallon, coll. "Epoques", 1990, chapitre XX : "Face à l'angoisse collective, le roi de Raison" ; CROUZET, Denis, "Les fondements idéologiques de la royauté d'Henri IV", Avènement d'Henri IV. Quatrième centenaire. Colloque III, Pau-Nérac 1989, Pau, Association Henri IV, 1989, p. 176.

7 CORVISIER, André [dir.], Dictionnaire d'art et d'bistoire militaire, Paris, P.U.F., 1988, p. 6163 ; voir aussi TREVOUX, Dictionnaire universel francois et latin, Paris, Compagnie des libraires associés, 1752, t. VII, col. 319-320 ; MORERI, Le grand dictionnaire bistorique, Paris, Les librairies associées, 1759, p. 331-332; Encyclopédie ou dictionnaire raisonné des sciences, des arts et des métiers, Neufchastel, Samuel Faulche, 1765, t. XVI, p. 603-604.
} 
Languedoc, Henri de Montmorency-Damville, négocia une première trêve avec les protestants en avril-mai 1573 alors qu'il assiégeait la place languedocienne de Sommières ; il reprit les armes peu après et en signa une nouvelle en août suivant ; elle fut alors prolongée jusqu'au début de l'année 1574 afin de permettre l'application de l'Edit de Boulogne - cinquième édit de pacification refusé par les protestants méridionaux - et surtout afin de sceller l'alliance du gouverneur avec les milieux réformés ${ }^{8}$. Une telle pratique n'était pas propre au Languedoc puisqu'on la rencontre également en Dauphiné, lorsque le 28 mars 1589, le chef protestant Lesdiguières signifiait par une trêve un premier rapprochement avec le lieutenant général du roi Ornano, en réponse à la réconciliation Henri III - Henri de Navarre?. Les principales trêves de cette nature furent essentiellement le fait des dirigeants du royaume. Le 4 novembre 1586, Catherine de Médicis et Henri de Navarre accordaient une trêve dans la région d'Orléans et de La Rochelle le temps de leur rencontre : c'était une première étape dans la négociation vers le rapprochement du roi et du premier prince du sang ${ }^{10}$. Elle ne fut pas prolongée, mais une nouvelle trêve fut signée le 26 avril 1589 par Henri III et Henri de Navarre pour une année, le souverain et le chef de parti ayant alors décidé d'unir leurs armes ${ }^{11}$. Henri IV et Mayenne usèrent de la même pratique en 1593 pour donner un tour officiel à leurs négociations, et publièrent une trêve de suspension d'armes pour trois mois le 31 juillet 1593 dont le texte fut diffusé à l'ensemble du royaume, jusqu'à Toulouse où elle fut consignée dans les livres de la ville ${ }^{12}$. La trêve était donc un élément de la diplomatie militaire et partisane dont les protagonistes des guerres n'hésitaient pas à faire usage quand se profilait une réconciliation prochaine.

Cependant, nous avons pu repérer des trêves d'une autre nature en Midi toulousain, des trêves de labourage qui n'avaient pas comme ambition de sceller un rapprochement entre adversaires, mais de définir une sorte de droit de la guerre. Elles s'inscrivaient dans le même esprit que les trêves de Dieu médiévales qui avaient été le moyen pour l'Eglise de circonscrire l'usage de la violence au sein du milieu nobiliaire en excluant des combats les populations non armées et en interdisant l'usage des armes certains jours de la semaine ou certains mois de l'année ${ }^{13}$. Les trêves de labourage n'avaient pas d'autre ambition que de protéger le civil des combats, mais différait de ces textes médiévaux par les moyens employés, mais également par les autorités contractantes ${ }^{14}$.

Si au Moyen Age, l'Eglise fut l'actrice principale de ces trêves, à la fin des guerres de Religion, ce furent les autorités civiles et militaires, municipales et provinciales, qui investirent ce champ d'intervention. L'espace politique qui servait de cadre à ces accords était l'espace provincial : une grande partie des trêves fut soit négociée directement par les lieutenants généraux et gouverneurs de Languedoc et de Guyenne, soit placées sous leur autorité et ratifiées par une attestation finale une fois la négociation achevée ${ }^{15}$. Dans leur principe originel, ces actes étaient le

\footnotetext{
${ }^{8}$ DE VIC (dom) et VAISSÈTE (dom), Histoire générale de Languedoc, Toulouse, Privat, 1889, t. XI, p. 562-563, et t. XII, preuve $n^{\circ} 319$ : lettre du roi félicitant Montmorency-Damville pour la prise de Sommières et approuvant la trêve qui vient d'être signée.

${ }^{9}$ GAL, Stéphane, Grenoble au temps de la Ligue, Grenoble, P.U.G., 2000, p. 571.

${ }_{10}$ BnF., F-46883 (12) : Mandement du Roy pour la publication de la trêve et intermission des armes, pour punir ceux qui y contreviendront, Paris, G. Linocier, 1586, In.- $8^{\circ}$, 4f. [Saint-Maixent - 4 novembre 1586]

${ }^{11}$ BnF., F-46889 (5) : Declaration du roy sur la tresve accordee par sa maiesté au Roy de Navarre. Contenant les causes et preignantes raisons, qui l'ont meu à ce faire, imprimé à Tours, chez Jamet Mettayer imprimeur ordinaire du roi, 1589

12 Arch. mun. Toulouse, AA 20/237, p.596-602: Articles acordés pour la tresve generale de France en l'année mil v nonante troys ; Mayenne envoya le $1^{\text {er }}$ août 1593, le lendemain de la signature de la trêve, une lettre aux capitouls de Toulouse pour ordonner l'application de son contenu : arch. mun. Toulouse, AA 10/236, p. 595-596 : lettre de Mayenne aux capitouls $-1^{\text {er }}$ août 1593 .

${ }^{13}$ FAVIER, Jean, Dictionnaire de la France médiévale, Paris, Fayard, 1993, p. 715 ; dans les dictionnaires de Trévoux ou Moreri cités précédemment, la notion de trêve est systématiquement associée à celle de trêve de Dieu, signe de la persistance d'une mémoire de ces mesures pacificatrices médiévales.

${ }^{14}$ Nous donnons en annexe 1 les actes de trêve dits trêves de labourage, relevés pour le Languedoc et le Midi toulousain afin de définir les contours de cette production réglementaire.

15 arch. dép. Tarn, C 854 : trêve du Languedoc - mars 1588 : comme l'ensemble des trêves, celle-ci est signée d'abord par Guillaume de Joyeuse qui s'engage à l'appliquer et la faire respecter, puis dans les mêmes termes par Henri de
} 
fruit d'un accord passé entre les plus hautes autorités de la province, scindées en deux autour de leur opposition partisane : l'autorité des lieutenants du roi en province et de ceux qui en prenaient le titre pour le parti protestant ou la Ligue était ainsi engagée. En dessous de ces chefs de guerre provinciaux commissionnés par le roi ou les partis, l'application locale des trêves dépendait essentiellement des Etats provinciaux et des villes. A l'échelle du Languedoc, ce n'était pas tant l'assemblée générale que les circonscriptions régionales, les diocèses civils, qui avaient en charge l'application locale des règlements contenus dans les trêves et ainsi les négociations avec leurs visà-vis directs. Les diocèses civils étaient des Etats provinciaux en miniature, composés d'une assemblée pluri-annuelle de représentants des principales ville de leur ressort, dotés d'un bureau permanent - syndic, receveur, greffier, avocat, commissaires - et investis du devoir de répartition des impôts une fois qu'ils avaient été acceptés par le Etats de la province. S'ajoutait à cette fonction fiscale l'encadrement de la vie locale. Pour le Midi toulousain, les guerres de Religion furent un temps d'épanouissement politique de ces institutions provinciales, véritable moteur de la mobilisation financière et militaire, composante nouvelle de la décision politique sur les pays ${ }^{16}$. En Guyenne, les Etats de Comminges, de Quercy et du Rouergue présentèrent un engouement moins marqué pour cette modalité de règlement des conflits, mais s'y mêlèrent sur le tard. De la même manière que leur homologue languedocien, ces petits Etats provinciaux avaient manifesté des propensions à encadrer la guerre civile et s'investissaient alors dans sa résolution ${ }^{17}$. Le comté de Foix en fit autant par l'intermédiaire de son gouverneur, Jean-Claude de Lévis-Léran seigneur d'Audou, nommé par Henri de Navarre puis Henri IV. Enfin, quelques villes firent valoir une certaine indépendance dans ces négociations : Toulouse qui refusait d'être associée aux députés provinciaux, L'Isle-Jourdain ou le Mas-Grenier qui étaient places tenues par des gouverneurs protestants et jouant le rôle de capitales régionales dans l'espace gascon.

Les trêves de labourage furent ainsi le fait d'une politique régionale, patronnée par les représentants de l'autorité supérieure, mais appliquées localement par les députés des villes et des villages. Il ne nous semble pas d'ailleurs que les accords entre lieutenants du roi aient systématiquement précédé les accords au sein des pays. Il semblerait davantage qu'il y ait eu des initiatives concomitantes entre chefs de guerre et représentants des villes qui composaient l'entourage des gouverneurs : soit les décisions étaient prises en fonction des directives données par un des gouverneurs, soit elles étaient une ratification de propositions adoptées à l'échelle du petit pays. Cette conjonction de facteurs explique les raisons pour lesquelles les premières traces de trêves de labourage sont observées dans les diocèses civils languedociens de Narbonne, SaintPons et Béziers ${ }^{18}$. Ces contrées se trouvaient à la jonction de l'aire de domination du clan Joyeuse pour l'autorité royale puis ligueuse, et celle de Montmorency pour l'autorité protestante puis royale. C'est dans ce cœur incertain et conflictuel du Languedoc, entre haut et bas pays, que semble s'être élaboré, au sein des autorités locales, les premières trêves de labourage, réponse à l'urgence d'un conflit omniprésent et de plus en plus dévastateur. Ces modèles de trêve furent ensuite repris par les chefs des deux partis, étendus à la province, puis copiées aux échelons inférieurs par les autres diocèses civils. Du Languedoc, ils semblent s'être étendus au reste du Midi toulousain et à la Guyenne. Le contenu même des textes était quasiment identique d'un acte à l'autre, suggérant la circulation de copies, reprises et augmentées en fonction de la situation locale et étendant l'influence des trêves à l'ensemble du périmètre toulousain. L'année 1590 représente une véritable accélération dans ce processus, puisque c'est à partir de cette époque que

\footnotetext{
Montmorency, gouverneur du Languedoc sous l'obéissance d'Henri de Navarre ; l'ensemble des pièces était transmis avec ces certificats aux autorités locales, ici albigeoises].

16 Pour les détails sur l'évolution des diocèses civils dans la guerre, voir : SOURIAC, Pierre-Jean, Une société dans la guerre civile. Le Midi toulousain au temps des troubles de religion, thèse de doctorat, Université de Paris IV-Sorbonne, 2003, 3 vol.

17 SOURIAC, René, Décentralisation administrative dans l'ancienne France. Autonomie commingeoise et pouvoir d'Etat, 15401630, Toulouse, les Amis des Archives, 1992, 2 vol.

18 Trêves du 20 décembre 1586 et du 25 juillet 1587 [Mém. Soc. Carcassonne, p. 372 ; Ménard, Nîmes, vol. 4, p. 249 ; arch. dép. Hérault, C 8399].
} 
nous commençons à voir se multiplier les trêves en Guyenne comme en Languedoc : neuf actes en 1590 contre deux en 1588 et deux en 1589, huit actes en 1591, encore six en 1592 avant de décroitre. Ainsi, une fois que les positions ligueuses et royales se fixèrent définitivement dans la région, l'engrenage des négociations de trêve put véritablement se mettre en marche ; c'est paradoxalement au moment de la plus grande intensité des conflits que les ennemis cherchèrent à régir les pratiques de guerre par ces accords de trêve.

En Haut-Languedoc, les diocèses civils placés au cœur des zones de confrontation réussirent à encercler leur ressort par des accords multi-partites, signe d'un souci ordonné de protéger l'ensemble de leur territoire. Prenons le cas du diocèse civil de Toulouse. En février 1590, les députés catholiques de l'assiette diocésaine signaient un accord de trêve de labourage conjointement aux députés catholiques des diocèses de Mirepoix, Rieux et des comtés de Comminges et Couzerans, avec les envoyés protestants du comté de Foix : c'était toute la lisière sud du diocèse que l'on cherchait à préserver des malheurs de la guerre. En juillet suivant, ces mêmes députés signaient un même texte avec les protestants de Caraman, enclave calviniste au cœur du Lauragais : l'est du diocèse se trouvait alors sous la protection de ce droit de la guerre. Ces actes étaient repris à l'automne suivant, avec les mêmes interlocuteurs et étendus à l'ensemble du Haut-Languedoc à partir d'avril 1591 : ainsi, tout l'est toulousain se voyait régi par ces trêves de labourage. Cet encadrement civil de l'action militaire se maintint jusqu'à la pacification finale, et fut relayé à l'ouest du diocèse de Toulouse par des accords de même nature avec les protestants de L'Isle-Jourdain à partir de 1593. Ainsi, l'ensemble de la périphérie toulousaine directe, celle du diocèse civil, fut progressivement gagnée par une volonté de limitation du fait d'armes. Les catholiques du diocèse civil d'Albi firent de même, en négociant avec leur ennemi direct de Réalmont, et ceux plus éloignés de Castres et du Rouergue.

\section{Un droit des civils face aux soldats}

Dans un contexte de guerre civile où le voisin était devenu l'ennemi, ces accords de trêve se présentent pour les institutions locales comme un moyen de dissocier poids des conflits et vie civile. Cette dissociation se fondait sur l'invention d'un droit original que les actes passés entre ennemis devenus membres $d u$ contraire parti et non plus papistes ou hérétiques, ne cessaient de rappeler. Nous en donnons la nature exacte dans l'annexe 3 de ce présent article ${ }^{19}$.

A l'origine de ces trêves, se trouvait la protection des civils, et plus particulièrement la protection des travailleurs des champs, en réaction à la soldatesque qui ne cessait de sillonner les campagnes à la recherche de quelques rapines, de paysans à capturer pour les mettre à rançon ou de récoltes à dévaster afin d'en priver l'adversaire ${ }^{20}$. L'interdiction de s'en prendre à un laboureur, à son matériel agricole ainsi qu'à sa récolte remonte à l'origine même des trêves, qui étaient bien plus que de simples trêves de labourage au sens strict : les accords entre partis antagonistes concernaient l'ensemble des travaux des champs et non les simples phases de labourage et de moisson $^{21}$. L'ensemble de l'appareil productif se trouvait ainsi garanti de toute saisie, de tout vol

\footnotetext{
${ }^{19}$ Cf. annexe 3 : nature des articles des trêves de labourage en Midi toulousain (1586-1595).

${ }^{20}$ Pour une approche générale de l'incidence de la guerre sur le milieu rural : DESPLAT, Christian (dir.), Les Villageois face à la guerre (XIV'-XVIII siècle), Toulouse, P.U.M., 2002.

21 Premierement est accordé que toutz laboureurs, mesnagers et personnes faisant ordinaire prefession de laboraige pourront librement sens estre molestés ny ampeschés par les gens de guerre soict de guerre soit de cheval [sic] ou de pied, ne ceulx habitans des villes et lieux clos pourtans les armes, fere la recolte des fruictz de la present année et autres labouraige jusque au premier jour de janvier prochain inclusivement, sens que lesdits gens de guerre ne autres leur puyssent donner aulcung empechement tant en leurs personnes que bestiaulx soict muletz, juments, beouf₹, vaiches, pourceaulx ne en aulcune espece de bestail soict gros ou menu qu'il apartient a gentilhome, gens de guerre, marchans, borgeois on autres de quelque qualite ou condition que ce soict, soict il pour tailhes, contributions, arreirages on autrement pour quelque pretexte que ce soict saulf tant seulement par la seulle voix de la justice lors que tel cas le requiera, anquel cas les executions necessaires ce soict sens assitance de soldats ou gens de guerre. Et pourront lesdits gens de labeur et travailh, aller en toute seurette eulx et leurs familhes en villaiges ouvertz et autres maisons destinees a l'exercice de l'agriculture, recolte desdits fruictz. sens que
} 
et de toute destruction gratuite par le soldat. Les paysans étaient autorisés à aller travailler au dehors de leur village sans risquer leur vie et leurs biens, y compris en passant à proximité de lieux occupés par une garnison ennemie de celle qui occupait leur village. Il en allait de même lors des convoyages des grains et les laboureurs étaient libres de choisir leurs lieux de stockage pour lesquels les militaires ne devaient en théorie exercer aucune forme de contrainte. Le travailleur de la terre se trouvait ainsi sous la protection d'un accord juridique reconnu par les chefs militaires et les instances civiles des deux partis en présence, à la condition que lui-même ne fasse pas montre d'un comportement belliqueux et ne transporte pas d'armes avec lui. L'enjeu originel de ces textes fut ainsi la sauvegarde de l'outil de production agricole mis à mal depuis plus de vingt ans de guerre. L'apparition presque spontanée de ces trêves dès 1586 et leur généralisation après 1588 tendrait à montrer que les méridionaux, du moins les Languedociens, avaient déjà mis à profit l'expérience des années passées pour trouver une voie de protection minimum de leur lieu de vie. D'une certaine manière, ces accords de trêve indiqueraient la maturité précoce du pays pour une solution négociée de paix civile dès le début de la huitième et dernière guerre de Religion.

Avec le temps, ces mesures de protection des paysans méridionaux s'affinèrent, allongeant d'autant le dispositif réglementaire contenu dans les trêves. Par effet de miroir, ces clauses ajoutées au fil des actes témoignent des difficultés que rencontrait quotidiennement le petit peuple des campagnes. A chaque signature de trêve, prisonniers et biens volés devaient être restituées sans versement de rançon et sans délais ; l'interdiction de commettre à l'avenir de tels actes était naturellement renouvelée. Hommes et matériels étaient également protégés de toute saisie pour retard fiscal par simple décision militaire : les soldats de l'un ou de l'autre camp ne pouvaient arguer de l'impôt, ordinaire ou extraordinaire, pour confisquer les biens du récalcitrant, comme la justice le pratiquait jusque-là. Le dérèglement dans la perception fiscale, les abus des soldats et la priorité accordée à la production agricole se combinaient pour créer ce régime d'exception dans lequel les procédures judiciaires traditionnelles détournées par les hommes de guerre étaient dénoncées et où il était nécessaire de réaffirmer le rôle exclusif de la justice civile. Le paiement des dîmes fut également traité par ces textes : obligation de la payer en nature contrairement aux exigences nouvelles des officiers ecclésiastiques, obligation de la payer en sa recette habituelle. Ce dernier point cherchait à consacrer l'occupation territoriale des partis par le respect de la géographie fiscale, y compris pour les impôts ecclésiastiques levés en milieu protestant.

L'annexe 3 montre ensuite que ces trêves de labourage ne cessèrent d'étendre le champ des protections individuelles à un nombre toujours plus important de catégories socioprofessionnelles. Pêcheurs et activités de pêche furent protégés dès les premières trêves, notamment sur le modèle des actes signés entre Narbonne et Montpellier où la mer était un foyer de revenus pour les populations littorales. Par la suite, toute personne susceptible de se déplacer et offrant prise à un raid militaire fut placée sous la protection du régime des trêves de labourage : les marchands pour reprendre les termes des traités, les bouchers et leur bétail, les artisans de toute sorte, les ouvriers agricoles à la recherche de travail ou au milieu des champs, les chirurgiens, les médecins, les apothicaires, les femmes et les enfants, les ecclésiastiques, les receveurs fiscaux chargés d'argent, tout le petit monde des campagnes et des villes méridionales que l'on croisait sur les chemins au milieu des guerres civiles bénéficiaient d'un article en leur faveur ${ }^{22}$. S'ajoutent à ces

l'on puisse rien prandre desdits fruictz, sy ce n'est de leur gré et volonté ny de leurs meubles a peine de la vie [arch. dép. Hérault, C 8399 : trêve de labourage signée entre les diocèses de Narbonne, Béziers et Saint-Pons - 1587].

22 Tous medecins, sieurs, gens et appoticaire allans ou revenans pour servir aulcungs d'ung et d'aultre party jouiront de mesmes privilieges que lesdits lavoureurs comme fairont aussy les charpentiers et massons residans aux champs [sans] faire la guerre ny proffections des armes; les bouchiers, leur bestailh, les pecheurs et leur pecherie seront en mesmes assurance et libertté que les laboureurs et labouratgie ; aussy ne sera donné aulcungz troubles aulx personnes des mesniers, leurs servitteurs, voitaire ou charoy des bledz, ou farines portés on raportés du moulin, ny au bestailh ou charrettes quy les porteront, ains seront en ce faisant treuves sans armes en mesmes assurance que les laboureurs; [arch. mun. Toulouse, AA 20/206, p. 537-541 : trêve de labourage entre les députés des diocèses de Toulouse, Albi, Castres et Lavaur, le comté de Caraman - Saint-Félix, 8 octobre 1591] ; Est aussy acordé que toutes jeunes enfans de l'aage de quinze ans et au desous ne pourtans armes a feu et n'en faisant poinct proufession ouverte ne pourront estre prins, 
individus les sauniers et leur salin, les meuniers et leur moulin. Dans ces catégories, nulle mention d'un rang social ou d'une fonction politique, mais des identifications professionnelles, ou par âge et sexe pour les femmes et les enfants. De fait, cet élargissement du champ de compétence semble avoir été très pragmatique, les ajouts successifs répondant à des situations locales liées à la conjoncture ou à l'activité des pays. La protection des citadins réfugiés à la campagne pour avoir fui la peste qui sévissait dans leur ville souligne le caractère très modulable de la réglementation : à Toulouse, la recrudescence de l'épidémie à partir de 1586-87 obligea la ville à prendre des mesures d'hygiène publique et incita une partie de l'élite à quitter les demeures urbaines ${ }^{23}$. Les négociateurs de trêve étaient ainsi réactifs aux événements qui marquaient leur quotidien et les reportaient dans leurs règlements. Comme les actes de trêves étaient ensuite diffusés et recopiés d'année en année et d'une région à l'autre, il se produisait une forme de sédimentation réglementaire qui aboutissait à un élargissement progressif de la protection juridique portée par les trêves. Il est fort à parier que si la guerre ne s'était pas interrompue dans les années 1593-1594, ce champ de compétence n'aurait cessé de s'accroître. Parallèlement, ce pragmatisme souligne quelles furent les priorités dans la protection civile et les catégories sociales les plus touchées ou, du moins, celles jugées comme indispensables au maintien de l'activité économique des pays.

Une fois que ces garanties étaient énoncées, les actes de trêves cherchaient à réglementer le respect des clauses ainsi arrêtées. La première condition à la bonne application des trêves était que le civil n'adoptât pas le comportement du soldat : tout port d'armes, toute agressivité étaient ainsi prohibés. Mais dans une époque où les routes étaient peu sûre, où la guerre civile depuis plus de vingt ans avaient habitué les civils à l'autodéfense, il est peu probable qu'une telle obligation aient été respectée. De même, les métairies isolées avaient été dans l'ensemble plus ou moins fortifiées par quelques guérites, éventuellement à des fins partisanes, mais essentiellement contre le brigandage qui s'était développé entre la fin des années 1570 et le début des années $1580^{24}$. Fortifications de fortune face à la nécessité du temps, elles furent le prétexte à des attaques qui nécessitèrent des précisions sur la nature des fortifications des métairies à partir de $1590^{25}$. Ainsi, des tensions naissaient entre la définition du civil désarmé soucieux malgré tout de sa propre protection, et les arguments des soldats qui se réfugiaient derrière ces limites réglementaires pour justifier certaines exactions.

De telles divergences interprétatives imposèrent de définir des niveaux de responsabilité dans l'application des trêves, d'abord par l'engagement des lieutenants généraux donc de la hiérarchie militaire, puis par la nomination de commissaires d'application dès 1588 , et enfin, à partir de 1590, par la mise en avant des gouverneurs de place et des autorités consulaires. Ainsi,

arrestés, ne ranconnés de mesmes que toutes faimes, chacun en son party de quelque qualité qu'elles soienct, leurs serviteurs et chambrieres les acompanhant sans armes a feu, chevaulx, bagues, robes et hardes destinées pour leurs vestemens et ornement ne seront empechees ny inquietées ains uzeront de la mesme seureté contenue et porté par lesdits articles pour lesdits jeunes enfans et laboureurs [arch. mun. Toulouse, AA20/208, p.542-551 : trêve du Languedoc - 8 novembre 1591] ; Les ecclesiastiques d'ung et d'autre party pourront aller librement avec leurs serviteurs, hardes et chevaulx ez. lieux de leur party pour la vizite de leurs egliszes, function de leurs charges et mesnagerie de leurs biens, sans qu'ilz.puissent estre pillez, prins, ny ranconnés, encores qu'ilzpassent par les terres du contraire party s'ilz ne font la guerre ou soient treuves saysis de pacquetz lettres et billetz. concernant l'estat et faict de la guerre auquel cas pouront estre retenuz.pour estre cognen de la veritté et estre procedé contre eulx par la voye de justice et non aultrement [arch. mun. Toulouse, AA 16/269, f ${ }^{\circ} 279 \mathrm{v}-284 \mathrm{r}$ : trêve de Guyenne entre Villars et Matignon - juin 1592]

${ }^{23}$ ROUCAUD, Joseph, La peste à Toulouse. Des origines an XVIII e siècle, Toulouse, librairie J.Marqueste, 1919 , p. 82. Aussi les personnes de quel estat et condition que soient que pour esvicter le danger de peste, cas advenant, fut en aulcunes villes et lieux (ce que Dieu ne veuilhe) soy retirant aux maisons champestres seroit en icelles en toute seureté, tout ainsi que les laboureurs avec leurs familhe et biens [arch. dép. Hérault, C 8399 : continuation de la trêve conclue entre les députés du diocèse de Toulouse, Cintegabelle, Gaillac-Toulza, le fort de Beauteville, Saint-Michel-de-Lanes, La Garde-Canihac, Marcaing et Peyrefitte, et les députés du Comté de Foix - 23 octobre 1590].

${ }^{24}$ Pour les activités de brigandage en Languedoc, se reporter à : NAUZIERES, Raymond, "Le capitaine Bacou, son séjour et sa mort à Brassac, Tarn, 1583-1586", Revue du Tarn, t. 22, 1905, p. 200-214, 276-288.

${ }_{25}$ Qu'on ne pourra prandre aulcung bestail gros ny menu des villes villages ou metaries, encores qu'elles soient gardees par guerittes pour ce deffandre des voleurs, ne pourront estre vexés par quelque ocasion que ce soict, encore bien qu'on ne leur veuilhe bailher des vivres, pourveu que ne soict par passaige d'armée auquel cas seront teneux d'bobeyr sans estre offencés ne saquachés [arch. mun. Toulouse, AA20/208, p.542-551 : trêve du Languedoc - 8 novembre 1591] 
toutes les formes de représailles d'ordre privées étaient interdites : en cas de contravention à la trêve, il fallait en référer au capitaine, au juge ou au consul le plus proche, qui lui-même devait saisir le commissaire d'application afin de régler le litige. Si la menace était trop grande en raison d'une troupe incontrôlable dans les environs du village, il fut autorisé dans deux traités de trêves de 1590 de jouer du tocsin pour rassembler les habitants. Dans ce cas également, il était fait usage de l'action collective pour éviter la vendetta personnelle, mais cela renvoyait aux pratiques passées de la guerre et fut abandonné rapidement. Il est nécessaire de souligner l'importance que représentait une telle interdiction dans une société qui avait été confrontée aux troubles et à l'autodéfense depuis les années 1560 : ces règlements de trêve imposaient un retour au judiciaire, certes par le biais d'un droit exceptionnel lié à la guerre civile, mais en s'efforçant d'éloigner le sujet méridional de la logique du règlement de compte personnel et violent. A côté des chefs de guerre, les autorités civiles, celle des villes et des villages, en lien avec les commissaires d'exécution des trêves, furent systématiquement choisies à partir de 1590 comme garantie d'application $^{26}$. Leur responsabilité judiciaire et financière fut engagée dans les poursuites contre les contrevenants aux trêves, dans les libérations de prisonniers, restitutions de biens ou extradition des voleurs hors de leurs murs. Ainsi, les négociateurs de trêves cherchèrent le plus souvent à faire reposer l'exécution de leurs accords sur les autorités locales, signe d'une société civile cherchant à sortir par elle-même des malheurs de la guerre. A une seule reprise en 1589, lors d'une trêve de suspension d'armes, il fut question de livrer des otages pour obtenir des garanties dans l'application du texte : ce procédé ne fut par la suite plus jamais employé, la trêve de labourage se voulant permanente et non ponctuelle, ce qui aurait obligé à d'incessants échanges d'otages.

De tels accords ne doivent pourtant pas laisser penser qu'il n'y avait plus de guerre en Midi toulousain, au contraire. Les années 1588-1590 virent se définir les positions antagonistes des ligueurs méridionaux et des protestants derrière Henri de Navarre puis Henri IV. En 1589, le coup de main ligueur de l'évêque de Comminges et d'une partie du Parlement sur la ville de Toulouse amena un regain de violence et aboutit au siège de la capitale languedocienne par l'autre chef ligueur de la province, Guillaume de Joyeuse. Après cette phase d'intimidation, il réussit à faire passer la ville dans l'orbite de la Sainte-Union parisienne ${ }^{27}$. En 1592, le fils de Guillaume de Joyeuse, Antoine-Scipion, mit le siège devant la petite ville de Villemur-sur-Tarn avec l'espoir de s'ouvrir une tête de pont vers Montauban ; la mobilisation des deux camps fut considérable sur quatre mois, de l'été à l'automne, et vit la défaite des ligueurs ${ }^{28}$. Enfin du printemps à l'été 1595 , le duc de Ventadour, lieutenant général en Languedoc pour Henri IV vint dans la banlieue toulousaine où il joignit ses forces à celles de Matignon, lieutenant général en Guyenne, pour contraindre le dernier des Joyeuse, Henri, ancien capucin reconverti dans le métier des armes, à accepter la paix henricienne ${ }^{29}$. Entre ces moments bien connus de la huitième guerre civile, le pays fut soumis aux garnisons des places et aux maigres escarmouches. Ainsi, malgré les trêves, la guerre continuait : l'enjeu de ces règlements était alors d'écarter le civil des actions militaires

\footnotetext{
${ }^{26}$ Et ou aulcunes personnes suspectes passeront esdites villes et lieux ou ez. environs d'icelles, d'ung et d'autre party et conduisant bestail de quelque espece ou nature que ce soict, les consulz, desdites villes et lieux seront tenus les arrester avec ledit bestail jusques a ce qu'ilz. ayent faict souffizament apparoir icelluy n'estre desrobé contre la teneur de la present tresve et ou lesdits personnes vouldroient fere resistance seront poursuivis par toute voye d'bostilité et a son de tocquesain si besoing est comme ennemis publicques et les recellateurs seront poursuivis et punis de mesmes et a ces fins sera permis aux interessés en toute liberté de poursuivre le recouvrement du bestail a eulx prins et d'en pouvoir faire en toute asseurance les requisitions et protestations necessaires contre lesdits consulz et seindicz. [arch. dép. Hérault, C 8399 : continuation de la trêve conclue entre les députés du diocèse de Toulouse, Cintegabelle, Gaillac-Toulza, le fort de Beauteville, Saint-Michel-de-Lanes, La Garde-Canihac, Marcaing et Peyrefitte, et les députés du Comté de Foix - 23 octobre 1590].

${ }^{27}$ GREENGRASS, Mark, "The Sainte Union and the provinces : the case of Toulouse", The Sixteenth century journal, vol. XIV, n 4, 1983, p. 469-496.

28 "Copie d'une lettre contenant le vrai et entier discours, tant du siège de Villemur que de la défaite de Monsieur le duc de Joyeuse", Mémoires de la Ligue, Amsterdam, Arkstée et Merkus, 1758, t. IV, p. 157-169 ; DE VIC et VAISSETE, Histoire générale de Languedoc, Toulouse, Privat, 1880, t. XI, p. 250-254.

${ }^{29}$ De Vic et Vaissète, Histoire générale..., op. cit., p. 856.
} 
quand il n'était pas plongé au cœur du théâtre d'affrontement. En cas de siège, le pays était mis en coupe réglé et les villages des alentours devaient contribuer à ravitailler les soldats ; quand une compagnie passait dans une région, elle devait également pourvoir à son ravitaillement et son hébergement. Mais quand les grandes opérations commandées par les chefs provinciaux s'éloignaient, les autorités locales cherchaient à limiter l'incidence des militaires qui étaient laissés en garnison. Les trêves de labourage n'étaient donc pas des préambules à la pacification, mais une réglementation qui posait comme premier principe la défiance des populations locales à l'égard de la soldatesque et la nécessité de la maintenir à une distance respectable.

La relative réussite de ces mesures s'observe a contrario dans les regains de violence que connurent les zones méridionales peu touchées par ce mouvement. En Comminges, apparurent dès 1591 les Ligues campanères, c'est-à-dire des syndicats de défense contre les soldats qui regroupèrent une soixantaine de communautés autant dans le piémont pyrénéen que dans le bas pays $^{30}$. En Périgord, Limousin, Quercy et jusqu'en Agenais, se dressèrent également des assemblées de communes, 21 au total, de l'automne 1593 à l'automne 1595, afin d'organiser les communautés villageoises pour lutter contre les razzias, les vols et les enlèvements commis par les soldats ${ }^{31}$. Au sud comme au nord du gouvernement de Guyenne, des communautés manifestaient ainsi leur lassitude de la guerre en ayant recours à la violence par la transformation de leur lieu de vie en territoire retranché interdit aux armées. Ces mouvements s'appuyaient sur des pratiques d'autodéfense héritées des guerres précédentes, non pas pour défendre une cause partisane, mais pour circonscrire les malheurs de la guerre dans un territoire étranger à leur quotidien. Ces associations furent plus ou moins légales, mais ne sont pas à prendre comme une manifestation supplémentaire des guerres de Religion. Au contraire, selon nous, ces ligues et assemblées s'inscrivent dans la même logique du refus de la guerre que les trêves de labourage observées ailleurs dans le Midi. Elles illustrent une réaction d'une société non pacifiée face aux derniers feux des guerres civiles et le rejet violent par les populations villageoises des capitaines les plus irréductibles dans la poursuite des conflits. Il est permis d'associer cette dernière flambée de violence au faible nombre de trêves de labourage rencontrée en Guyenne. Concernant le Comminges, seul les zones limitrophes avec le diocèse de Toulouse et le nord du Comté de Foix signèrent quelques traités à partir de 1590. Parallèlement, les marges occidentales du comté ouvertes sur le Béarn ainsi que celles ouvertes sur l'espace montagnard traditionnellement plus incertain, ne connurent aucun texte de ce type ${ }^{32}$. Pour le Quercy et le Limousin, nos recherches ne nous ont pas permis de découvrir d'actes de trêves, mais comme pour le Comminges, si ces provinces furent mêlées à ces négociations, elles ne développèrent pas une logique systématique comparable à celle rencontrée dans les diocèses civils de Toulouse ou d'Albi. Nous sommes donc en présence de deux manifestations antinomiques face la lassitude de la guerre, signe que l'adoption de ces trêves de labourage n'allaient pas nécessairement de soi et relevait d'un comportement relativement original à l'espace languedocien.

\section{L'invention d'un dialogue}

De la décision de la trêve à son application sur le terrain de la guerre civile, le chemin était long à parcourir. Accepter de rencontrer l'ennemi, accepter de suspendre l'affrontement ou du moins de ne pas lui livrer une guerre totale si l'on use d'un terme anachronique, pouvait être pris

\footnotetext{
${ }^{30}$ SOURIAC, René, Décentralisation dans l'ancienne France, Toulouse, Les Amis des Archives, t. I, p. 231-238.

${ }^{31}$ BERCE, Yves-Marie, Histoire des Croquants. Etude des soulèvements populaires au XVII siècle dans le sud-ouest de la France, Genève, Droz, 1974, t. 1, p. 264.

32 POUJADE, Patrice, Identité et solidarités dans les Pyrénées. Essai sur les relations humaines (XVI-XIX siècle), Aspet, Pyrégraph, coll. "Aldu", 2000, p. 120 ; voir aussi les recherches de Serge Brunet sur les accords commerciaux entre pays pyrénéens, les lies et passeries, véritable espace protégé par les montagnards eux-mêmes pour assurer une sécurité dans la circulation des biens: BRUNET, Serge, Les prêtres des montagnes. La vie, la mort, la foi dans les Pyrénées centrales sous l'Ancien Régime, Aspet, Pyrégraph, coll. "Universatim", 2001, p. 119-120
} 
pour de la faiblesse et être rejeté par les tenants de positions plus radicales. Le 30 novembre 1589, lorsque Guillaume de Joyeuse vint à Toulouse alors qu'il était gouverneur du Languedoc commissionné par le duc de Mayenne depuis Paris, il venait de signer une trêve de labourage avec Henri de Montmorency, gouverneur de la même province pour le compte d'Henri IV $^{33}$. Il comptait faire enregistrer l'acte par le Parlement de Toulouse et s'opposer par la même occasion à l'installation d'une confrérie du Saint-Sacrement dans la ville malgré les propositions des conseillers. Galvanisé par un prêche du provincial des minimes, mobilisé dans une procession menée par l'évêque de Comminges portant la cuirasse et l'épée avec le titre de gouverneur de la ville pour la Sainte-Union, le peuple toulousain prit le chemin de l'archevêché où résidait Guillaume de Joyeuse qui dut s'enfuir et se réfugier à Balma. Le dénouement de l'affaire vit pourtant Joyeuse triompher puisqu'il obtint après un court siège le départ de l'évêque de Comminges, mais sa négociation de trêve avec l'ennemi juré qu'était, pour les Toulousains, Henri de Montmorency avait été un prétexte suffisant pour conspuer un chef de guerre jugé jusque-là comme légitime ${ }^{34}$.

Dans le même esprit, mais avec des conséquences moins graves, son fils subit quelques quolibets après la signature d'une trêve en 1594.

\title{
Sur la tresve faite par Joyeuse avec Montmorency- s.d.
}

De peur des coups, il quita son espée,

Pour prendre un froc, et feit bien la pipée.

Ores qu'il est aus armes rapelé,

Il sent encor son capussin pelé :

Car il fait tresve, afin qu'il se repose.

Moine, ou guerrier, c'est tousjours mesme chose.

\author{
Autre huitain - s.d. \\ Voyés si Tolosans sont gens bien entendus, \\ Qui faschés du barnois, et du bast qui les blesse, \\ Nagueres ont choisi entre rendus \\ Un gentil Capussin pour chef de leur noblesse. \\ Ce n'est pas mawvais choix : car par ruse et finesse \\ Il se tire avec eus du hazard des combats : \\ Et laissant a la tresve apointer touts debats, \\ Pend au croq le procés du presche et de la messe. 35
}

Ce capussin qui préféra poser ses armes plutôt que les user pour la défense de sa cause était Henri de Joyeuse, comte du Bouchage, entré dans les ordres après avoir été veuf. Il quitta l'habit monastique à la fin de l'année 1592 suite à la mort de son frère Antoine-Scipion au siège de Villemur-sur-Tarn, et assura la direction des affaires ligueuses en Languedoc jusqu'à la paix de Folembray. Le choix qu'il fit de signer une trêve avec Montmorency le 31 janvier 1594 se voit ici expressément critiqué, preuve de sa couardise et de sa paresse.

\footnotetext{
${ }^{33}$ De Vic et Vaissète, Histoire générale..., op. cit., t. XI, p. 792-798.

34 Sur les mauvais rapports entre Toulouse et le gouverneur de Languedoc, voir JOUANNA, Arlette, "Protection des fidèles et fidélité au roi : l'exemple de Henri Ir de Montmorency-Damville", in DURAND, Yves, Hommages à R. Mousnier, clientèles et fidélités en Europe à l'époque moderne, Paris, P.U.F., 1981, p. 279-296 ; TIEVANT, Claude, Le gouverneur de Languedoc pendant les premières guerres de religion (1559-1574), Henri de Montmorency-Damville, Paris, Publisud, 1993, 372 p.

35 BnF., Fr. 3960 : poèmes satiriques anonymes et non datés.
} 
Enfin, au-delà de la réputation, accepter un acte de trêve représentait pour le chef de guerre une forme de soumission aux autorités civiles qui n'était pas toujours facile à accepter. Nous donnons à titre d'exemple, la réponse que fit un petit capitaine catholique de l'Albigeois placé sous l'autorité du gouverneur du pays, le baron d'Ambres, au capitaine Moysset, commissaire d'application des trêves en 1588.

\begin{abstract}
Capitaine Moysset, j'ay trouvé ceans une lettre vous estre signé : a laquelle je ne faictr. point de responce pour ce que ce n'est point a vous a qui je dois rendre conte de mes actions, je ne vous recougnois pas digne ny capable de cela : ce que j'ay promis a monsieur d'Ambres et a messieurs du pays d'Albiges, je l'observeray relligieusement : et le tiendray inviolablement. Depuis que je suis retiré ici, je n'en suis point sorty pour donner empeschement a aucuns arrentiers spirituelz. ny temporelz: vous resembles les anguilles de Melun, vous criez devant qu'on vous escorche, je vous avise devant que je n'ay promis que pour moy, et n'ay respondu et ne respons que pour ceux qui sont sous mon autorité ou sont compris mes valetz, car le reste est bien petit : pour les autres faicts comme vous pourrez; je me recomende; de Montclar ce 5 juillet.

Le vostre comme au paravant.

signé : LAVERNEE ${ }^{36}$
\end{abstract}

En 1588, ce petit chef de guerre catholique en garnison à Monclar refusait de reconnaittre l'autorité de cet homme nommé par les députés de la trêve et prétendait n'obéir qu'à son supérieur militaire. On comprend ici l'importance que revêtait l'adhésion des gouverneurs de pays et de province dans les traités de trêve ainsi que le chemin qu'il restait à parcourir en ce domaine en 1588. Sans ce soutien, ce commissaire des trêves d'Albigeois n'aurait probablement pas servi à limiter les exactions des soldats. Le dialogue interconfessionnel que réussirent à instituer les procédures de trêve fut ainsi l'aboutissement d'efforts et de persévérance : il dut s'affranchir de l'intransigeance ambiante, des accusations de lâcheté, et des conflits d'autorité. Ces trois niveaux de blocage présentent à eux seuls toute l'étendue des limites des trêves de labourage et leur précarité dans une situation où le soldat conservait le dernier mot. Mais la reconduction et la généralisation de ces actes tout au long de la huitième guerre indiquent que ces verrous ont été dépassés ou du moins n'ont pas découragé les autorités concernées par la mise en place de ce nouveau dialogue avec l'ennemi.

Dépasser ces blocages imposés par la guerre commença d'abord par trouver des lieux de rencontre entre communautés adverses : l'annexe 2 fournit la carte de ces villes et bourgs de négociation de trêve en Midi toulousain. Dans la région d'Albi, Castres et Lavaur, les petites capitales de pays accueillirent le plus souvent les députés catholiques et protestants : Albi, Réalmont, Cordes, Castres, Puylaurens. Dans le Toulousain, la ville rose refusa toujours de voir pénétrer en ses murs de tels adversaires, et la pratique voulut que les négociations aillent se tenir dans les bourgs situés aux marges des frontières confessionnelles : Grisolles en lisière de Gascogne et Montalbanais, Tarabel et Saint-Félix en lisière du Lauragais protestant, Cintegabelle ou Saverdun en lisière du Comté de Foix. Capitales régionales et zones de contact furent alors les théâtres de ces discussions, instituant un ballet de plénipotentiaires des deux partis au cœur des zones à risque. Des passeports étaient alors signés par les gouverneurs provinciaux ; la municipalité de Toulouse et les institutions provinciales défrayaient les députés choisis pour se rendre au lieu de négociation préalablement défini ${ }^{37}$. Dans l'ensemble des pièces comptables des

\footnotetext{
36 Arch. mun. Tarn, C 855 : lettre reçues par le commissaire de la trêve - 5 juillet 1588.

${ }^{37}$ Henry de Joyeuse, gouverneur et lieutenant general pour le roy en Languedoc a tous ceulx qui besoing sera salut. Nous vous mandons et ordonnons laisser librement et seurement passer et repasser jusques au nombre de quatorze au quinze parsonnes a cheval depputes de Guyenne, Quercy, Montauban et Rouergue, ainsi que nous avons permis et permettons par ces presantes de venir en la ville de Tholouze, pour avec les depputés de notre party, prouferer et s'assembler pour l'observation de la tresve de ceste province et desdits pais sans que leur puisse estre faict ou donné, ny a rien que leur apartient, soict en venant, sejournant ou retournant, aulcung arrest ny empechement avec toute faveur et ayde.

Faict a Tholouze ce xi mars mil v' nonante treitze. De Joyeuse signé. Et plus bas par mondit seigneur Aldebert

Arch. mun. Toulouse, AA 20/232, p. 592 : passeport d'Henri de Joyeuse pour les négociateurs de la trêve - 1593.
} 
administrations méridionales de cette époque, on rencontre des frais de députés de trêves qui devinrent un poste permanent de dépenses de 1588 à $1594^{38}$.

Les négociateurs de ces trêves étaient issus des corps des villes et des assemblées d'Etats : il s'agissait ainsi du milieu de la bourgeoisie municipale toulousaine et des principaux personnages des villes et bourgs du plat pays. En 1591, les capitouls de Toulouse envoyaient à Puylaurens puis à Saint-Félix, pour négocier avec les protestants, noble Bernard de Lafont, bourgeois de Toulouse, donc ancien capitoul, et Mathieu de Carcasse, docteur et syndic de la ville ${ }^{39}$. En 1592, c'était au tour de Michel Garrigues, avocat au Parlement et capitoul, de signer avec le même Lafont l'acte de trêve de Saint-Félix ${ }^{40}$. En 1593, la ville envoyait à Grisolles encore une fois Bernard de Lafont accompagné de Durant d'Abatia, docteur et avocat au Parlement ainsi que de Jacques Puget, bourgeois de la ville ${ }^{41}$. En Albigeois, les négociateurs catholiques appartenaient à ce même milieu : un lieutenant du juge d'Albi, un bourgeois de la ville et un consul de Rabastens en 1591 ; un licencier en droit d'Albi, le premier consul de Lisle-d'Albigeois et un notaire royal d'Albi en $1592^{42}$. Tous ces personnages avaient été au préalable députés de la partie catholique du diocèse civil d'Albi. A Toulouse comme dans le plat pays, ce personnel correspondait à l'élite locale qui s'était investie dans le financement et l'encadrement de la guerre depuis les années 1560. Consuls de communauté et députés des Etats provinciaux, hommes de justice ou commerçants, ce sont eux qui assurèrent la mobilisation des pays derrière les principaux chefs de guerre en servant d'interface entre ressources fiscales et besoin des soldats. Leur engagement partisan fut déterminant dans l'enracinement de la guerre civile et ils furent pour cela associés à la décision militaire, tant du côté catholique que du côté protestant ${ }^{43}$. Or, le refus de la guerre vint de ces mêmes instances, de ce même milieu : la fin de la décennie 1570 et les débuts de la huitième guerre entre 1584 et 1586 furent probablement des années où s'opéra un profond renversement dans les mentalités politiques de la région. La lassitude du conflit et la crainte de plus en plus en sensible de la ruine totale des villes comme des campagnes toulousaines conduisirent à la dénonciation d'une situation intolérable.

En amont de la négociation, les administrations locales préparaient leur délégation et leurs arguments pour faire admettre leurs revendications. Des cahiers et autres mémoires étaient rédigés à l'intention des députés, énumérant les points sur lesquels il était possible de faire des concessions, et ceux qu'il fallait défendre. L'essentiel des remarques dénonçait les violations des trêves précédentes par ceux $d u$ contraire parti, et les exigences de nouvelles garanties qui allaient

\footnotetext{
38 Pour le diocèse civil de Toulouse, un tel poste de dépense apparaît dès 1588, lorsque Jean Falcon, lieutenant d'appeau au comté de Caraman et Gaillard Croset, tous deux consuls de Saint-Félix, furent délégués pour les catholiques du diocèses pour aller négocier la trêve, avec en sus le paiement d'une escorte de douze soldats et d'un sergent ainsi que le remboursement de leurs nombreux courriers; il en fut de même les années suivantes [arch. dép. Haute-Garonne, C 696 : compte du syndic du diocèse de Toulouse - 1588].

39 Arch. mun. Toulouse, AA16/264, $\mathrm{f}^{\circ} 277 \mathrm{r}$ : délégations des capitouls pour la négociation de la trêve à Puylaurens 11 avril 1591 ; AA20/204, p. 535 : procuration des capitouls en faveur de Bernard de Lafont député de la ville pour négocier la trêve à Saint-Félix - 8 octobre 1591.

40 Arch. mun. Toulouse, AA 16/267, $\mathrm{f}^{\circ} 274 \mathrm{v}-275 \mathrm{r}$ : procuration donnée à Michel Garrigues docteur et avocat au Parlement et capitoul, et à Bernard de Lafont bourgeois, pour la négociation de la trêve - 20 juin 1592 ; AA 16/268, $\mathrm{f}^{\circ} 279 \mathrm{r}-\mathrm{v}$ : ordonnance des députés signataires de la trêve à Saint-Félix - 24 juin 1592.

${ }^{41}$ Arch. mun. Toulouse, AA16/269, $\mathrm{f}^{\circ} 284 \mathrm{r}$ : procuration des capitouls de Toulouse pour la négociation de la trêve à Grisolles - 29 mars 1593.

${ }^{42}$ Arch. dép. Tarn, C 860 : mémoire pour les négociateurs catholiques de la trêve de Réalmont - septembre 1591 ; arch. dép. Tarn, C 862 : mémoire pour les négociateurs catholiques de la trêve de Lautrec - 27 octobre 1592.

43 Pour se faire une idée de ce lien entre administration civile et effort de guerre, voir : GREENGRASS, Mark, "Henri de Montmorency-Damville et l'administration des armées provinciales de Languedoc", Province et pays du Midi au temps d'Henri de Navarre, 1555-1589, acte du colloque de Bayonne, 7-9 octobre 1988, Biarritz, Association Henri IV, 1989, p. 103-123 ; SOURIAC, Pierre-Jean, "Les urgeans affaires de la ville. Défendre Toulouse durant la première guerre de Religion, 1562-1563", Revue d'bistoire urbaine, n³, juin 2001, p. 39-65 ; GARRISSON, Janine, Protestants du Midi, 1559-1598, Toulouse, Privat, 1980.
} 
encore accroître les règlements en vigueur ${ }^{44}$. Les négociations en elles-mêmes n'ont pas laissé de très nombreuses sources, et seules celles discutées dans le diocèse d'Albi en 1588 nous sont parvenues : elles furent menées à trois niveaux, d'abord avec les voisins protestants de Réalmont, puis avec la petite capitale régionale de Castres, et enfin avec l'ensemble des députés des diocèses civils de Haut-Languedoc ${ }^{45}$. Les deux premières négociations portèrent exclusivement sur la protection des laboureurs et la mise en application concrète de décisions prises par les lieutenants généraux à l'échelle de la province. La troisième réunion visait à étendre ces modalités d'application à toute une partie de la province, mais fut parasitée par l'opposition des délégués protestants et catholiques d'Albi sur le paiement des garnisons. Les premiers exigeaient qu'une partie des communautés catholiques contribue à l'entretien de leurs garnisons car ils ne possédaient pas assez de territoire et donc de foyers fiscaux pour lever suffisamment d'impôts et honorer l'état des garnisons ordonné par leur gouverneur, le vicomte de Turenne. Les catholiques s'y opposèrent, arguant que les partis devaient se limiter aux ressources des terres qu'ils contrôlaient ; les protestants opposèrent à cet argument la levée effective des troupes qui chercheraient à se payer sur le civil si la solde n'arrivait pas. La question de ces places de sûreté régionales fut renvoyée aux gouverneurs de province qui résolurent l'affaire sans que l'on sache comment. On mesure ici combien les trêves de labourage n'étaient en rien des traités de paix visant à démilitariser le pays, mais le moyen de s'entendre pour contenter le soldat et limiter ses exactions. Cette entente allait jusqu'à porter sur le devant de la scène le problème des moyens de la guerre, signe qu'autour des problèmes militaires il devenait possible de discuter.

Une fois que les trêves étaient signées, deux commissaires d'application, un de chaque confession, étaient nommés par diocèse civil. Il s'agissait en général de capitaines ou de nobles locaux dont l'autorité devait servir la fonction qui leur était assignée : nous avons vu précédemment le capitaine Moysset en Albigeois en 1588, qui était également consul de Lisled'Albigeois. En 1591, la trêve générale de la province nommait à ce postes les deux gouverneurs d'Albigeois, Louis de Voisins baron d'Ambres pour les catholiques, Georges d'Alary seigneur de Tanus pour les protestants ${ }^{46}$. Pour essayer de cerner exactement leur rôle, suivons le seigneur d'Encuns, député catholique nommé commissaire par le maréchal de Joyeuse dans le diocèse de Toulouse en 1590.

\section{Travail d'un commissaire des trêves - juin 1590 à mars 1591}

Sources : arch. dép. Hérault, C 8399 [deux cahiers tenus par le seigneur d'Encuns]

- Juin 1590 : audition de sept plaintes de violation de la trêve.

- Juillet 1590 : visite les villes catholiques pour vérifier que les récoltes se font sans trop de problèmes ; audition de trois plaintes.

- Août 1590 : audition d'une plainte.

- Septembre 1590 : audition d'une plainte.

- Octobre 1590 : déplacement dans le diocèse pour communiquer les articles de la nouvelle trêve faite en Languedoc ; rencontre des émissaires de D'Audou, gouverneur du comté de Foix, à Cintegabelle du 19 au 23 octobre. Audition de deux affaires.

- Janvier 1591 : audition de deux plaintes; se rend à Caraman sur des avertissements d'exaction.

- Février 1591 : nouvelle assemblée à Cintegabelle pour l'entretien de la trêve : il se charge de convoquer l'ensemble des lieux catholiques pour le 18 février ; un accord est signé le 22 février après négociation.

\footnotetext{
${ }^{44}$ Nous avons trouvé trois cahiers de ce type dressés par le diocèse d'Albi pour leurs commissaires : arch. dép. Tarn, C 854 : mémoire pour les députés du diocèse d'Albi pour la négociation de la trêve - s.d. [1588] ; C 860 : idem septembre 1591 ; C 862 : idem - 27 octobre 1592. Pour la ville de Toulouse, nous avons trouvé un mémoire de ce type : arch. mun. Toulouse, AA20/245, p. 619-621 : instruction aux députés de Toulouse pour la négociation de la trêve à L'Isle-Jourdain - s.d. [1594].

45 Arch. dép. Tarn, C 854 : assemblée de négociation de trêve tenue à Albi entre députés catholiques (Albi) et protestants (Réalmont) du diocèse civil - $1^{\text {er }}$ juin 1588 ; arch. dép. Hérault, C 8389 : assemblée de négociation de trêve tenue à Castres entre les députés catholiques du diocèse d'Albi et les députés protestants du diocèse de Castres - 7 juin 1588 ; arch. dép. Hérault, C 8389 : assemblée de négociation de trêve tenus à Venès (Lautrec) entre des députés des deux confessions du Haut-Languedoc - 11-19 novembre 1588.

46 Arch. mun. Toulouse, AA20/208, p. 542-551 : trêve du Languedoc - 8 novembre 1591.
} 
- 2 mars 1591 : arrive à Tarabel, lieu de résidence juge quand il traite une affaire concernant Caraman.

- 3 mars 1591 : envoi de lettres aux consuls des environs pour apporter leurs plaintes à Tarabel.

- 4 mars 1591 : décision de tenir l'assemblée à Caraman et non à Tarabel.

- 5 mars 1591 : arrive à Caraman sur ordre de Joyeuse pour faire appliquer la trêve ; il siège avec le seigneur de Deyme, son collègue nommé par Montmorency-Damville. Ils reçoivent les plaintes des habitants du lieu sur les violations de la trêve. Ils auditionnent douze plaignants et écrivent aux communautés des alentours pour qu'ils envoient leurs plaintes.

- 6 mars 1591 : toujours à Caraman. Personne ne vint.

- 7 mars 1591 : toujours à Caraman. Audition de 21 plaintes.

- 8 mars 1591 : renouvellement de la publication de la trêve.

- 12-15 mars 1591 : vol de blé à Mazères qu'il cherche à faire restituer.

- 16 mars 1591 : arrive à Terrecques, pour rencontrer le seigneur de Rogoyrans, commissaire du parti protestant pour donner ordre aux vols commis à Mazères. Lors du retour, alors qu'il était avec des protestants venus à la conférence, il rencontra des cavaliers de Mazères bien montés et armés qui firent tous leurs effortz. a nous donner dessus et quoy que ledit Regoyrans les voulsisse arrester, ne luy fut jamais possible de maniere que si n'eussions rebroussé chemin comme fismes a toute haste droit a la maison de Terrenques la ou nous saulvasmes et fusmes poursuyvis jusques la dedans, nous estions ou mortz ou prisonniers et nous attendirent par apres en chemin pensant nous en retournerions par la, mais nous en prinsmes un autre droict a Cintegabelle ou il nous failleut coucher.

Ce périple entre Lauragais et pays de Foix rend compte de la nature du travail de ces commissaires : entendre les plaintes des particuliers pour violation de la trêve lors d'auditions publiques, passage de lieu en lieu pour y tenir ses audiences, enregistrement des plaintes, jugement rapide en général sans avis contradictoires, et enfin entente avec les consuls ou le capitaine du lieu pour faire appliquer sa décision. Ces commissaires ne disposaient pas de force armée et ils devaient témoigner d'un grand art de négociation et de persuasion pour arriver à leur fin, notamment quand la garnison d'une ville était mêlée à l'affaire. La bonne entente avec le commissaire du contraire parti était alors primordiale, mais n'empêchait pas certains risques comme le montre l'aventure arrivée au seigneur d'Encuns dans les environs de Cintegabelle. La nature des affaires traitées relevait du simple brigandage : vol de chevaux ou de bétail, emprisonnement de paysan, recel de biens volés,...

Ces commissaires achevaient ainsi l'édifice judiciaire extraordinaire créé dès 1586 pour protéger le civil des exactions du soldat. L'accord de trêve de labourage fixait le droit et réglementait les devoirs de chacun, principalement des soldats ; les commissaires recevaient le pouvoir de juger la bonne application de ce droit et de prendre les mesures de rétorsion adéquates. L'enjeu était la création d'un recours pacifique face aux violences militaires afin d'éviter ainsi qu'une violence d'ordre privée viennent affaiblir un corps social déjà mal en point. Il s'agissait également de créer une réglementation de coexistence entre civils et militaires en dépassant la simple question confessionnelle. L'entente entre catholiques et protestants fondait ce nouvel ordre social, dans lequel l'ennemi désigné était le soldat et non plus celui du contraire parti.

\section{Conclusion}

Nous n'avons pas le moyen de mesurer le rapport entre plaintes et affaires traitées par les commissaires, donc le niveau de réussite de ces trêves et le respect général de ce droit ainsi créé. Cependant, selon ce que nous avons pu apercevoir des pratiques générées autour de ces accords, leur intérêt est à comprendre dans une perspective plus large. Les trêves furent une voie de discussion entre ennemis par le biais des institutions civiles régionales qui cherchèrent à nouer des contacts par des modalités de négociation encore inédites jusque-là. Elles furent un moyen de mettre à distance la guerre sans aborder la question religieuse, protestants comme catholiques se mettant d'accord pour condamner le soldat en prenant acte des divisions confessionnelles nées au milieu du siècle et reconnues dans leur implication territoriale. Le débat sur les garnisons du diocèse d'Albi soulignent cette nouvelle géographie méridionale admise comme un acquis, principal résultat de la discorde civile. Pour ces raisons, les trêves de labourage furent une 
préparation progressive à la paix de religion mise au crédit d'Henri IV. En forçant le trait, nous pourrions y voir une forme précoce de sécularisation des guerres de Religion transformées en simples guerres civiles, tant les élites méridionales impliquées dans ces règlement cherchèrent à transposer le problème social au problème religieux : l'activité militaire fut montrée comme plus insupportable aux hommes du Midi toulousain que le différend confessionnel. Si le pays resta sur le pied de guerre jusqu'en 1596, date à laquelle fut signée la paix de Folembray qui consacrait la soumission des ligueurs languedociens, les armes s'étaient quasiment tues à partir de 1593, suite à l'échec ligueur lors du siège de Villemur. A l'exception du regain militaire du printemps 1595, les trêves de labourage se transformèrent progressivement en trêve de suspension d'armes entre les principaux chefs de guerre régionaux. En ce sens, ces trêves s'inscrivirent dans un mouvement de pacification militaire de la région, débuté dès le milieu des années 1580 et achevé en 1596. L'Edit de Nantes, de son côté, vint seulement se surimposer à des pratiques qui avaient préalablement banni du quotidien méridional les méfaits de la guerre civile : à Toulouse et dans sa région, les sujets du roi avaient déjà accepté de concevoir la fracture catholico-protestante comme un pis aller et la guerre civile comme un fléau suffisant pour justifier la réunification du corps social. Nous ne prétendons pas interpréter les trêves de labourage comme une causalité unique dans la réussite relative de l'Edit de Nantes, mais dans le cas du Midi toulousain, elles furent une étape déterminante dans le chemin vers la paix. Elles mirent fin à la guerre avant de réglementer la coexistence confessionnelle et surent canaliser la haine croissante du civil contre le soldat par l'invention de recours légaux. Ces derniers se fondèrent sur un code juridique extraordinaire lié à la conjoncture, mais limitant les réactions d'autodéfense et de violence qui, ailleurs, furent de nouveaux ferments de troubles civils, notamment dans les régions voisines qui ne connurent pas ces trêves. Forme originale de règlement des conflits, ces trêves témoignent de la vitalité des institutions locales qui surent passer du rôle d'animatrices des guerres à celui de garant d'une nouvelle paix civile. Elles furent pour cela de précieux auxiliaires au pouvoir henricien dans sa politique du retour à l'ordre. 
Annexe 1 : actes de trêves de labourage et trêve de suspension d'armes en Languedoc et Midi toulousain (1586-1595)

N.B. : les trêves marquées en italiques correspondent aux trêves de suspension d'armes précédent la pacification finale, les autres aux trêves de labourage.

\begin{tabular}{|c|c|c|c|c|c|c|c|}
\hline Date & Source & Espace concerné & $\begin{array}{l}\text { Contractant } \\
\text { catholique }\end{array}$ & $\begin{array}{l}\text { Contractant } \\
\text { protestant }\end{array}$ & Autorité de caution & Lieu de rencontre & $\begin{array}{c}\text { Dates } \\
\text { d'application } \\
\end{array}$ \\
\hline $\begin{array}{c}20 \text { décembre } \\
1586 \\
\end{array}$ & $\begin{array}{l}\text { Mém. Soc. Carcassonne, p. } \\
372\end{array}$ & Diocèses de Narbonne, Saint-Pons et Béziers & & & & & \\
\hline $\begin{array}{l}20 \text { décembre } \\
1586\end{array}$ & $\begin{array}{l}\text { Ménard, Nîmes, vol. 4, p. } \\
249\end{array}$ & Diocèses de Nîmes et Beaucaire & & & & & \\
\hline 25 juillet 1587 & \begin{tabular}{|l|} 
Arch. dép. Hérault, C \\
8399
\end{tabular} & Diocèse de Narbonne, Saint-Pons, Béziers & & & Joyeuse et Montmorency & & $\begin{array}{l}25 \text { juillet } 1587-1 \\
\text { janvier } 1588 \\
\end{array}$ \\
\hline mars 1588 & Arch. dép. Tarn, C 854 & Languedoc & $\begin{array}{l}\text { Guillaume de } \\
\text { Joyeuse }\end{array}$ & $\begin{array}{l}\text { Henri de } \\
\text { Montmorency }\end{array}$ & & & \\
\hline 16 nov. 1588 & Arch. dép. Tarn, C 854 & Diocèse d'Albi & & & Joyeuse et Montmorency & Venez & \\
\hline 26 avril 1589 & BnF., F46889 (5) & Royaume & Henri III & Henri de Navarre & & & Un an \\
\hline 30 août 1589 & $\begin{array}{l}\text { Arch. dép. Hérault, C } \\
8399\end{array}$ & Languedoc & Antoine de Joyeuse & $\begin{array}{l}\text { Henri de } \\
\text { Montmorency }\end{array}$ & Le roi & Mas-de-Pardaillan & \begin{tabular}{|l|}
30 août, 30 \\
décembre 1589
\end{tabular} \\
\hline 28 janvier 1590 & Arch. dép. Tarn, C 857 & Languedoc & Antoine de Joyeuse & $\begin{array}{l}\text { Henri de } \\
\text { Montmorency }\end{array}$ & & & $\begin{array}{l}28 \text { janvier } 1590 \text { - } 1 \\
\text { janvier } 1591\end{array}$ \\
\hline 5 février 1590 & Arch. dép. Tarn, C 857 & Languedoc & Antoine de Joyeuse & $\begin{array}{l}\text { Henri de } \\
\text { Montmorency }\end{array}$ & & \begin{tabular}{|l|} 
Peyriès (diocèse de \\
Narbonne) \\
\end{tabular} & $\begin{array}{l}1 \text { février } 1590-1 \\
\text { février } 1591\end{array}$ \\
\hline 7 février 1590 & $\begin{array}{l}\text { Arch. dép. Hérault, C } \\
8399\end{array}$ & $\begin{array}{l}\text { Diocèses de Toulouse, Mirepoix, Rieux, Couzerans, } \\
\text { comté de Foix ; approuvée par les Etats de } \\
\text { Comminges en mars } 1590 .\end{array}$ & Diocésains & Diocésains & $\begin{array}{l}\text { Joyeuse et Montmorency } \\
\text { M. de Selles, lieutenant du } \\
\text { roi dans le comté de } \\
\text { Pamiers }\end{array}$ & $\begin{array}{l}\text { Cintegabelle [métairie } \\
\text { de Baulhas] }\end{array}$ & \\
\hline 22 juillet 1590 & $\begin{array}{l}\text { Arch. dép. Hérault, C } \\
8399\end{array}$ & Sénéchaussée de Lauragais et comté de Caraman & & & Joyeuse et Montmorency & $\begin{array}{l}\text { Saint-Papoul [maison } \\
\text { du Carla] }\end{array}$ & \\
\hline 20 août 1590 & Arch. dép. Tarn, C 858 & Diocèses d'Albi et Castres & Diocésains & Diocésains & Joyeuse et Montmorency & Lautrec (diocèse d'Albi) & \\
\hline 19 octobre 1590 & Arch. dép. Tarn, C 858 & Diocèses de Lavaur et Saint-Papoul & Diocésains & Diocésains & Joyeuse et Montmorency & \begin{tabular}{|l|}
$\begin{array}{l}\text { Crozilles (diocèse de } \\
\text { Lavaur) }\end{array}$ \\
\end{tabular} & \\
\hline 23 octobre 1590 & Arch. dép. Hérault, C8399 & Diocèse de Toulouse et comté de Foix & $\begin{array}{l}\text { Diocésains et } \\
\text { citadins }\end{array}$ & $\begin{array}{l}\text { Diocésains et } \\
\text { citadins }\end{array}$ & Joyeuse et d'Audon & $\begin{array}{l}\text { Cintegabelle [métairie } \\
\text { de Baulhas] }\end{array}$ & \\
\hline 2 nov. 1590 & Arch. dép. Hérault, C8399 & Diocèse de Toulouse et comté de Caraman & $\begin{array}{l}\text { Diocésains et } \\
\text { citadins }\end{array}$ & $\begin{array}{l}\text { Diocésains et } \\
\text { citadins }\end{array}$ & Joyeuse et Montmorency & Tarabel [Lauragais] & \\
\hline 14 nov. 1590 & Arch. dép. Tarn, C 858 & Languedoc & députés de Joyeuse & $\begin{array}{l}\text { députés de } \\
\text { Montmorency }\end{array}$ & & & Un an \\
\hline 18 mars 1591 & Arch. dép. Tarn, C 859 & Diocèse d'Albi et Rouergue & députés d'Albigeois & $\begin{array}{l}\text { députés du } \\
\text { Rouergue }\end{array}$ & Matignon et Joyeuse & Cordes & $\begin{array}{l}1 \text { mars } 1591-1 \text { mars } \\
1592\end{array}$ \\
\hline 12 avril 1591 & Arch. dép. Tarn, C 859 & Haut-Languedoc & Diocésains & Diocésains & Joyeuse et Montmorency & \begin{tabular}{|l|} 
Puylaurens \\
\end{tabular} & \\
\hline 29 avril 1591 & Arch. dép. Tarn, C 859 & Diocèse d'Albi & députés d'Ambres & députés de Paulin & & Albi & \\
\hline 22 sept. 1591 & Arch. dép. Tarn, C 860 & Diocèse d'Albi & $\begin{array}{l}\text { députés du diocèse } \\
\text { (Albi) }\end{array}$ & $\begin{array}{l}\text { députés du diocèse } \\
\text { (Réalmont) }\end{array}$ & Joyeuse et Montmorency & Réalmont & \\
\hline 22 sept. 1591 & Arch. dép. Tarn, C 860 & Diocèses d'Albi et Castres & députés des diocèses & députés des diocèses & Joyeuse et Montmorency & Réalmont & \\
\hline
\end{tabular}




\begin{tabular}{|c|c|c|c|c|c|c|c|}
\hline Date & Source & Espace concerné & $\begin{array}{l}\text { Contractant } \\
\text { catholique }\end{array}$ & $\begin{array}{c}\text { Contractant } \\
\text { protestant }\end{array}$ & Autorité de caution & Lieu de rencontre & $\begin{array}{c}\text { Dates } \\
\text { d'application } \\
\end{array}$ \\
\hline 3 octobre 1591 & Arch. dép. Tarn, C 860 & Diocèse d'Albi & $\begin{array}{l}\text { députés du diocèse } \\
\text { (Albi) }\end{array}$ & $\begin{array}{l}\text { député du baron de } \\
\text { La Guéppie }\end{array}$ & & & \\
\hline 8 octobre 1591 & $\begin{array}{l}\text { Arch. mun. Toulouse } \\
\text { AA20/206 }\end{array}$ & $\begin{array}{l}\text { Diocèses de Toulouse, Albi, Castres, Lavaur } \\
\text { et comté de Caraman }\end{array}$ & députés des diocèses & députés des diocèses & Joyeuse et Montmorency & Saint-Félix & \\
\hline 8 nov. 1591 & $\begin{array}{l}\text { Arch. mun. Toulouse } \\
\text { AA20/208 }\end{array}$ & Languedoc & Joyeuse & $\begin{array}{l}\text { Montmorency- } \\
\text { Damville }\end{array}$ & & $\begin{array}{l}\text { Plaine entre Olonzac et } \\
\text { Pépieux }\end{array}$ & Un an \\
\hline 3 juin 1592 & $\begin{array}{l}\text { Arch. mun. Toulouse } \\
\text { AA16/265 }\end{array}$ & Guyenne & Villars & & & & \\
\hline 26 avril 1592 & Arch. dép. Tarn, C 861 & Diocèse d'Albi & Ambres & & & & \\
\hline juin 1592 & $\begin{array}{l}\text { Arch. mun. Toulouse } \\
\text { AA16/269 }\end{array}$ & Guyenne & Villars & Matignon & Mayenne & Astafort & \\
\hline 24 juin 1592 & $\begin{array}{l}\text { Arch. mun. Toulouse } \\
\text { AA16/263 }\end{array}$ & Diocèse de Toulouse & députés toulousains & & & & \\
\hline 12 juillet 1592 & Arch. dép. Hérault, C8399 & Comté de Foix et villes voisines & $\begin{array}{l}\text { députés du diocèse } \\
\text { (Rieux) }\end{array}$ & $\begin{array}{l}\text { députés du comté de } \\
\text { Foix }\end{array}$ & \begin{tabular}{|l|} 
d'Audou, Montberauld \\
Taurignan, Joyeuse \\
\end{tabular} & Sieuras & \\
\hline 22 mars 1593 & Arch. dép. Hérault, C8399 & Quercy & députés des Etats & & & & \\
\hline 7 avril 1593 & Arch. dép. Hérault, C8399 & $\begin{array}{l}\text { Languedoc, Rouergue, Quercy, Mas-Grenier } \\
\text { et L'Isle-Jourdain }\end{array}$ & & & & Grisolles & $\begin{array}{l}\text { Application des } \\
\text { trêves précédentes } \\
\text { du Languedoc }\end{array}$ \\
\hline 25 juin 1593 & $\begin{array}{l}\text { Arch. mun. Toulouse } \\
\text { AA20/235 }\end{array}$ & Languedoc, L'Isle-Jourdain, Comminges & députés & Du Bourg & & L'Isle-Jourdain & $\begin{array}{l}\text { Application des } \\
\text { trêves précédentes } \\
\text { du Languedoc }\end{array}$ \\
\hline 31 juillet 1593 & $\begin{array}{l}\text { Arch. mun. Toulouse } \\
\text { AA20/237 }\end{array}$ & Royaume & Mayenne & Henri IV & & & Trois mois \\
\hline 31 janvier 1594 & $\begin{array}{l}\text { Arch. mun. Toulouse } \\
\text { AA20/242 }\end{array}$ & Languedoc & Joyeuse & Montmoreny-Damville & & Nissan et Corsan & Un an \\
\hline 9 février 1594 & $\begin{array}{l}\text { Arch. dép. Haute-Garonne, } \\
\text { C3662/38 }\end{array}$ & Guyenne & Villars & Matignon & & & \\
\hline mars 1594 & $\begin{array}{l}\text { Arch. dép. Haute-Garonne, } \\
\text { C3662 }\end{array}$ & Comminges et L'Isle-Jourdain & député du comté & Du Bourg & & & $\begin{array}{l}\text { Application des trêves } \\
\text { précédentes du } \\
\text { Languedoc }\end{array}$ \\
\hline 28 février 1595 & $\begin{array}{l}\text { Arch. mun. Toulouse } \\
\text { AA16/270 }\end{array}$ & Languedoc & députés de Joyeuse & députés de Montmorency & & Narbonne & $\begin{array}{l}\text { Prolongement de six } \\
\text { mois }\end{array}$ \\
\hline 4 avril 1595 & $\begin{array}{l}\text { Arch. mun. Toulouse } \\
\text { AA20/248 }\end{array}$ & $\begin{array}{l}\text { Comté de Foix et villes voisines } d u \\
\text { Languedor, Couserans et Comminges }\end{array}$ & députés de Joyeuse & $\begin{array}{l}\text { députés du comté de } \\
\text { Foix }\end{array}$ & & $\begin{array}{l}\text { Saverdun [métairie de } \\
\text { l'église de Fraidas] }\end{array}$ & \\
\hline
\end{tabular}


Annexe 2 : carte des lieux de signature de trêves de labourage en Midi toulousain

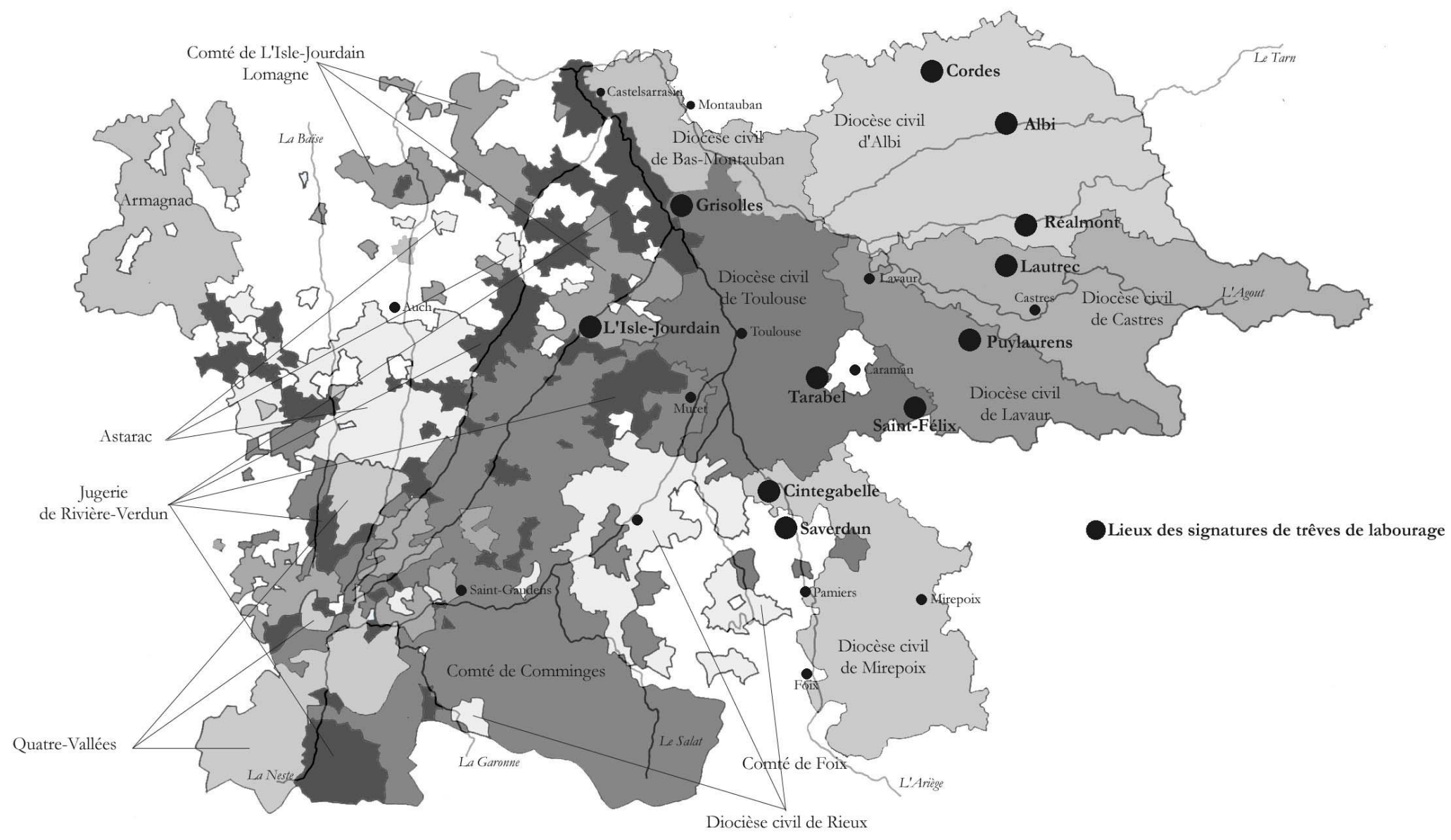


Annexe 3 : nature des articles des trêves de labourage en Midi toulousain (1586-1595)

\begin{tabular}{|c|c|c|c|}
\hline Article contenu dans l'acte de trêve & Occurrence & $\begin{array}{l}\text { Date de première } \\
\text { mention de l'article }\end{array}$ & $\begin{array}{c}\% \text { d'occurrence sur le } \\
\text { nombre total d'actes de } \\
\text { trêves }\end{array}$ \\
\hline Suspension d'armes & 5 & 1589 & 13,2 \\
\hline Démilitarisation des lieux & 1 & 1591 & 2,6 \\
\hline Protection des laboureurs & 23 & 1586 & 60,5 \\
\hline Protection du matériel agricole & 22 & 1586 & 57,9 \\
\hline $\begin{array}{l}\text { Interdiction d'exécution de justice } \\
\text { sur le matériel de labour }\end{array}$ & 3 & 1590 & 7,9 \\
\hline Protection des moissons & 12 & 1586 & 31,6 \\
\hline Liberté de choix du lieu de retraite & 2 & 1588 & 5,3 \\
\hline Liberté de circulation des laboureurs & 8 & 1586 & 21,1 \\
\hline Liberté de stockage des grains & 13 & 1586 & 34,2 \\
\hline liberté de circulation des grains & 12 & 1586 & 31,6 \\
\hline Liberté de circulation générale & 10 & 1589 & 26,3 \\
\hline Paiement de la dîme aux lieux habituels & 6 & 1586 & 15,8 \\
\hline Protection de la pêche & 7 & 1586 & 18,4 \\
\hline Protection des marchands & 8 & 1586 & 21,1 \\
\hline Protection des bouchers & 6 & 1588 & 15,8 \\
\hline Protection des salins & 2 & 1590 & 5,3 \\
\hline Protection des meuniers & 10 & 1590 & 26,3 \\
\hline Protection des artisans & 5 & 1590 & 13,2 \\
\hline Protection des ouvriers agricoles & 4 & 1590 & 10,5 \\
\hline $\begin{array}{l}\text { Protection des chirurgiens, médecins, } \\
\text { apothicaires }\end{array}$ & 2 & 1591 & 5,3 \\
\hline $\begin{array}{l}\text { Protection des réfugiés à la campagne en } \\
\text { cas de peste }\end{array}$ & 8 & 1590 & 21,1 \\
\hline $\begin{array}{l}\text { Protection des serviteurs, femmes, } \\
\text { enfants }\end{array}$ & 9 & 1590 & 23,7 \\
\hline Protection des ecclésiastiques & 3 & 1591 & 7,9 \\
\hline Protection des financiers & 1 & 1592 & 2,6 \\
\hline Interdiction de prise de montures & 3 & 1590 & 7,9 \\
\hline $\begin{array}{l}\text { Extradition des voleurs et contrevenants à } \\
\text { la trêve }\end{array}$ & 13 & 1586 & 34,2 \\
\hline Interdiction de représailles privées & 7 & 1590 & 18,4 \\
\hline $\begin{array}{l}\text { Nomination de commissaires } \\
\text { d'application }\end{array}$ & 17 & 1588 & 44,7 \\
\hline $\begin{array}{l}\text { Responsabilité des consuls dans le } \\
\text { respect de la trêve }\end{array}$ & 10 & 1590 & 26,3 \\
\hline $\begin{array}{l}\text { Responsabilité des chefs de guerre } \\
\text { dans le respect de la trêve }\end{array}$ & 5 & 1590 & 13,2 \\
\hline Tocsin pour poursuivre les contrevenants & 2 & 1590 & 5,3 \\
\hline Organisation des garnisons & 3 & 1588 & 7,9 \\
\hline $\begin{array}{l}\text { Libérations de prisonniers et } \\
\text { restitutions de biens }\end{array}$ & 12 & 1588 & 31,6 \\
\hline Interdiction d'achat de viande volée & 2 & 1590 & 5,3 \\
\hline Reconstruction de métairies & 1 & 1590 & 2,6 \\
\hline Définition des métairies fortifiées & 7 & 1590 & 18,4 \\
\hline $\begin{array}{l}\text { Dédommagement en cas de } \\
\text { contravention }\end{array}$ & 4 & 1590 & 10,5 \\
\hline Fin des contributions forcées & 7 & 1589 & 18,4 \\
\hline Otages & 1 & 1589 & 2,6 \\
\hline Envoi de la trêve aux voisins & 2 & 1591 & 5,3 \\
\hline Rançon des prisonniers de guerre & 1 & 1592 & 2,6 \\
\hline
\end{tabular}

